\title{
The value of the neuropsychological assessment for adults with Fetal Alcohol Spectrum Disorder: A case study
}

\author{
Joanne Sparrow ${ }^{1}$, Therese Grant ${ }^{2}$, Paul Connor ${ }^{3}$, and Nancy Whitney ${ }^{3}$ \\ ${ }^{1}$ School of Psychology, Family and Community, Seattle Pacific University, Seattle, WA, United States \\ ${ }^{2}$ Department of Psychiatry and Behavioral Sciences, University of Washington School of Medicine, Seattle, WA, United States \\ ${ }^{3}$ Alcohol and Drug Abuse Institute, Department of Health Sciences Administration, University of Washington School of Medicine, Seattle, WA, \\ United States
}

\begin{abstract}
Fetal Alcohol Spectrum Disorder (FASD) is an umbrella term that reflects the range of potential effects resulting from Prenatal Alcohol Exposure (PAE). Individuals with FASD may demonstrate cognitive, functional and adaptive challenges that are as debilitating as those experienced by individuals with the full fetal alcohol syndrome. This case study describes a young mother with PAE who was enrolled in a three-year intensive case management program and who was suspected of having FASD. Authors describe the neuropsychological battery that was administered and how assessment results were used to help members of a multidisciplinary team reframe their thinking and respond to the client's neuropsychological strengths and impairments by adjusting their language, expectations and interventions accordingly. Recognized as a valued member throughout the assessment and intervention process, the client learned to develop strategies that supported her autonomy and self-advocacy.
\end{abstract}

Since Fetal Alcohol Syndrome (FAS) was first identified in the United States in the early 1970s (Jones \& Smith, 1973; Jones, Smith, Ulleland, \& Streissguth, 1973), thousands of human and animal studies have demonstrated that alcohol is a teratogen that can cause pervasive brain-based impairments (Centers for Disease Control and Prevention [CDC], 2004a). Depending on ascertainment methods, the prevalence of FAS in the U.S. has been reported as 0.2 to 3.0 cases per 1,000 live births (CDC, 2004b). The rate of Fetal Alcohol Spectrum Disorders (FASD), an umbrella term reflecting the range of effects that may result from Prenatal Alcohol Exposure (PAE), is approximately 9.1 per 1,000 births (Sampson et al., 1997). Epidemiological studies estimate a combined prevalence of FAS and FASD in up to five percent of the U.S. population (May et al., 2009). There are no national statistics on the rates of FASD in Canada (Chudley et al., 2005), although studies have estimated its prevalence in small populations from approximately 7 per 1,000 live births in northeastern Manitoba (Williams, Odaibo, \& McGee, 1999) to 190 per 1,000 live births in an isolated Aboriginal community in British Columbia (Robinson, Conry, \& Conry, 1987). These figures suggest that FAS and FASD may have a significant impact on the work being done by professionals in the fields of education, mental health, public health, and vocational rehabilitation (Jirikowic, Gelo, \& Astley, 2010; O’Connor \& Paley, 2009; Paley \& O’Connor, 2011).
In order for a medical diagnosis of FAS to be made, evidence of facial dysmorphology, growth deficiencies, and central nervous system abnormalities must be documented (CDC, 2004a). Individuals with FASD do not always display signs of facial abnormalities or growth deficiency, yet they may demonstrate lifelong cognitive, functional, and adaptive problems that are as debilitating as those experienced by people with the full syndrome (Streissguth et al., 2004). Most people with FASD have IQs greater than 70 and are not usually classified as having an intellectual disability (Streissguth et al., 2004). Instead, the brain-based impairments typically seen in affected individuals are in the domain of executive functioning (e.g., planning and organizing behavior, goal-directed activity, problem-solving, generalizing from experience, and selfregulation) (Connor, Sampson, Bookstein, Barr, \& Streissguth, 2000; Mattson, Goodman, Caine, Delis, \& Riley, 1999; Rasmussen, 2005; Riley, Mattson, \& Thomas, 2009; Watson \& Westby, 2003), although deficits in attention, memory, communication, motor functioning, and adaptive behavior may also be present (CDC, 2004a; Chudley et al., 2005). FASD has been referred to as a "hidden disability," because when IQ is average or above and there are no obvious dysmorphic features, it is difficult to identify (CDC, 2004b). For this reason, affected individuals may have difficulty accessing services and supports.

Correspondence: Joanne Sparrow, Seattle Pacific University School of Psychology, Family and Community, 3307 Third Ave. West, Seattle, WA, United States, 98119. Telephone: 206-543-7155. E-mail: jsparrow@spu.edu

Financial support: Funded by the Washington State Department of Social and Health Services, Division of Behavioral Health and Recovery, Contract \#0965-69005. Keywords: fetal alcohol syndrome, fetal alcohol spectrum disorders, neuropsychological assessment, neurocognitive disorder 
In a landmark study, Streissguth and colleagues (1996) found that over $90 \%$ of adults with FASD had co-morbid mental health problems: slightly over half of the individuals struggled with depression, 29\% experienced psychotic symptoms, $43 \%$ had made suicide threats, and $23 \%$ had made suicide attempts. Other researchers have similarly found high rates of co-morbid mental health issues including bipolar disorder, substance abuse and dependence, suicidality, and psychosis (Barr et al., 2006; Famy, Streissguth, \& Unis, 1998; Huggins, Grant, O’Malley, \& Streissguth, 2008; O’Connor et al., 2002; Spohr, Willms, \& Steinhausen, 2007; Steinhausen, 1996; Steinhausen \& Spohr, 1998). These problems may contribute to and/or be a consequence of the difficult life circumstances typically experienced by individuals with FASD. Researchers who have studied the life course of adults with FASD report disproportionately high rates of adverse outcomes, including disrupted schooling, trouble with the law, substance abuse problems, inappropriate sexual behaviors, and confinements (Clark, Lutke, Minnes, \& Ouellette-Kuntz, 2004; Salmon \& Buetow, 2012; Spohr et al., 2007; Streissguth et al., 2004). Unfortunately PAE is often overlooked as a possible etiological factor when affected individuals present with these kinds of mental health issues and social problems. In fact, people with an undiagnosed FASD often receive diagnoses (and treatment) for one set of symptoms while other symptoms are missed or ignored (Brown, Connor, \& Adler, 2012).

In North America, diagnostic guidelines for FASD (CDC, 2004a; Chudley et al., 2005; Floyd, O’Connor, Sokol, Bertrand, \& Codero, 2005) emphasize that the brain damage caused by PAE is best assessed by standardized testing, which includes measures of neuropsychological functioning. Although diagnostic standards have long been in place, recognition of the importance of FASD assessment among adults is overdue. Understanding the impact of PAE on brain-behavior relationships creates a context within which to reframe an affected individual's maladaptive behaviors and respond to them with more appropriate interventions (Malbin, 2002). The neuropsychological assessment is an important first step toward learning to think differently about ways in which treatment and interventions may be tailored to better suit the needs of the affected individual.

The following case study describes our experience with an adult client we suspected of having FASD. The example highlights the benefits of conducting a comprehensive neuropsychological examination, and illustrates how such an assessment can be used to inform service delivery and ultimately affirm and support adults who have FASD. Approval to report this case study was obtained from the Washington State Institutional Review Board and informed consent was obtained from the client.

\section{Case Study}

\section{Background}

Nina (not her real name), a single, Hispanic woman in her mid-twenties, was enrolled in a three-year Home-Visitation Case Management program (hereafter referred to as HVCM) for pregnant or parenting women who abused alcohol or drugs during their most recent pregnancy. The goals of the program are to: (1) assist mothers in obtaining treatment, maintaining recovery and resolving issues related to their substance abuse; (2) link families with community resources; (3) assure that the children are safe and receiving appropriate health care; and (4) work with women towards eliminating the risk of having a future alcohol- or drug-affected child (Ernst, Grant, Streissguth, \& Sampson,1999; Grant, Ernst, \& Streissguth, 1999; Grant, Youngblood Pedersen, Whitney, \& Ernst, 2007).

At the time of HVCM enrollment, Nina had lost custody of two children as a result of her substance use and she was living in temporary housing. During the intake interview, the HVCM clinician, a licensed mental health counselor with a strong background in the field of FASD, learned that Nina's mother had consumed alcohol throughout the pregnancy with her (later confirmed by a family member), and that her early home life was characterized by chaos and the trauma of repeated abandonment. Nina reported that she experienced significant problems with language and learning throughout grade school and that she eventually dropped out of eighth grade; she had also been in treatment on multiple occasions for a substance abuse disorder, and had a history of petty crimes. As she grew older, Nina was victimized in physically violent and emotionally abusive relationships that mirrored her early experiences with caregivers. In spite of these traumatic experiences, Nina consistently demonstrated resiliency and a sense of humor, and she was eager to participate in the HVCM program. As she listened to Nina's history, the HVCM clinician recognized behaviors suggesting the possible effects of PAE. She then recommended that Nina be evaluated by a neuropsychologist with expertise in the assessment of adults with FASD so that everyone involved in the management of the case-including the client herselfcould develop a better understanding of how she processed information, solved problems, incorporated feedback and remembered things.

\section{Neuropsychological Testing}

Nina completed several hours of neuropsychological testing conducted by one of the co-authors (PC) who has expertise in working with adults with FASD. The assessment encompassed five domains of cognitive and behavioral functioning known to be affected by PAE: (1) intellectual and academic achievement; (2) learning, memory, and attention; (3) motor coordination; (4) executive functioning; and (5) mental health screening and adaptive functioning. The test battery (Table 1) consisted of measures sensitive to these effects of PAE (Aragon et al., 2008; Connor et al., 2000; Connor, Sampson, Streissguth, Bookstein, \& Barr, 2008; Fagerlund et al, 2012; Mattson, Delis, \& Jones, 1998; Olson, Feldman, Streissguth, 
Table 1.

Neuropsychological assessment: Domains assessed and tests administered

\begin{tabular}{|c|c|}
\hline Domain assessed & Tests administered \\
\hline Intellectual functioning and academic achievement & $\begin{array}{l}\text { - Wechsler Adult Intelligence Scale (WAIS-III); (Wechsler, 1997) } \\
\text { - Woodcock Johnson Tests of Achievement (WJ-III); (Woodcock, Mather, \& McGrew, } \\
\text { 2001) }\end{array}$ \\
\hline Learning, memory and attention & $\begin{array}{l}\text { - California Verbal Learning Test (CVLT-II); (Delis, Kramer, Kaplan, \& Ober, 2000) } \\
\text { - Rey Osterrieth Complex Figure Test (RCFT); (Meyers \& Meyers, 1995) } \\
\text { - Conner’s Continuous Performance Test (CPT); (Conners \& MHS Staff, 2000) }\end{array}$ \\
\hline Motor coordination & $\begin{array}{l}\text { - } \text { Grooved Peg Board (GPT); (Heaton, Miller, Taylor, \& Grant, 2004) } \\
\text { - } \text { Finger Tapping Test (FTT); (Heaton, Miller, Taylor, \& Grant, 2004) } \\
\text { - } \text { Grip Strength Test (GST); (Heaton, Miller, Taylor, \& Grant, 2004) }\end{array}$ \\
\hline Executive functioning & $\begin{array}{l}\text { - Trail Making Test (TMT); (Reitan, 1979) } \\
\text { - Controlled Oral Word Association Test (COWAT); (Heaton, Miller, Taylor, \& Grant, } \\
\text { 2004) } \\
\text { - Ruff's Figural Fluency Test (RFFT); (Ruff, 1988) } \\
\text { - Stroop Color and Word Test; (Golden, 1978) } \\
\text { - Auditory Consonant Trigrams Test (ACT); (Stuss et al., 1987) } \\
\text { - Wisconsin Card Sorting Test (WCST-4); (Heaton \& PAR Staff, 2003) }\end{array}$ \\
\hline Mental health screening and adaptive functioning & $\begin{array}{l}\text { - Symptom Checklist-90-Revised (SCL-R 90); (Derogatis, 1994) } \\
\text { - Vineland Adaptive Behavioral Scale (VABS); (Sparrow, Balla, \& Cicchetti, 1984) }\end{array}$ \\
\hline
\end{tabular}

Sampson, \& Bookstein, 1998; Pei, Job, Kully-Martens, \& Rasmussen, 2011; Rasmussen \& Bisanz, 2010).

The neuropsychological evaluation revealed significant deficits consistent with the clinical presentation of FASD. Nina's full scale IQ score fell within the range of mild mental retardation; in addition, her reading ability was at the fourth grade level, her receptive language skills were at the level of an 8-year-old, and her verbal memory was severely impaired. The neuropsychological assessment also yielded information about Nina's strengths and the ways in which she learned best and functioned most effectively. Test results revealed that she was able to benefit from feedback and apply this information to develop alternative solutions to problems. Nina also demonstrated an ability to learn new information, albeit slowly, and to apply this knowledge throughout a task. She also made extensive efforts to succeed at a variety of daily living skills despite her cognitive challenges.

In his report, the neuropsychologist recommended a number of functional treatment approaches that have long been supported by the literature and practice in the fields of special education and cognitive rehabilitation. These included: making the environment more user-friendly by using checklists, visual cues, color coding and labels; using notebooks and technology to aid memory; and training family members and service providers to use these accommodations in order to enhance autonomy and independence (Hutchinson \& Marquardt, 1997; Watson \& Westby, 2003; Weinberger, Dolan, \& Dolan-Templeton, 2009; West \& Niemeier, 2005). In addition, the neuropsychologist suggested that others: (1) use simple language while maintaining the content of the message; (2) provide clear rules and structure; (3) offer timely and appropriate feedback; (4) repeat information she was expected to learn and remember; and (5) provide lists for her to check off tasks as she completed them.

\section{Follow-Up: Multidisciplinary Team Process}

During the first meeting convened after the assessment was completed, the neuropsychologist used concrete language while reviewing the results of the assessment and helped Nina (and the HVCM clinician) understand that many of the difficulties she experienced managing her life were related to weaknesses in areas such as receptive language skills. The neuropsychologist also offered a number of recommendations that focused on her strengths. For example, he observed that Nina enjoyed using her cell phone so he taught her to use the calendar, note pad, and appointment notification functions as memory aids. At the end of the meeting, the HVCM clinician invited Nina to call her whenever she wanted to talk about the test results and how they were reflected in the day-to-day challenges she faced. Nina welcomed this offer and called the clinician several times in the following months.

During a second meeting, the HVCM clinician shared the results of the assessment with Nina's HVCM case manager and the child welfare, mental health, and housing service providers who were involved with Nina's case, and discussed the ways in which Nina's deficits impacted her ability to meet various agency requirements. She used as an example Nina's struggles to understand and respond appropriately to the written child custody court orders, and pointed out how Nina's difficulties made sense when interpreted within the context of her fourth grade reading ability. The HVCM clinician asked the providers to think 
differently about Nina and about how they might be able to adjust their expectations and create accommodations to better serve her (Malbin, 2002).

Nina participated in the second half of this meeting, during which providers used clear language to convey information accurately and help reduce the anxiety Nina typically felt when she had difficulty understanding the professionals working with her. Nina willingly contributed to this discussion, and by the end of the meeting, service providers recognized how they had overwhelmed her by presenting her with abstract and overly-detailed instructions and setting expectations that were often unrealistic. The meeting concluded with a discussion regarding the longterm services and support Nina would need in order to maintain custody of her children and provide a stable, nurturing home for them.

Using the trusted and secure relationship that she built with the HVCM staff as a base, Nina began to advocate for herself by informing friends, family members, and professionals in her life about how her brain worked and how she learned best, and by letting others know when she needed them to restate their comments or instructions using language that she understood. The HVCM case manager reminded Nina's service providers to monitor their use of vocabulary and sentence structure so that information was presented in ways that were easy to comprehend and remember. Table 2 provides examples of terminology service providers used, prior to the neuropsychological assessment, that was abstract and generally confusing for Nina, contrasted with the more understandable and useful language that they utilized afterward.

Table 2.

Examples of abstract versus concrete language

\begin{tabular}{|c|c|}
\hline Abstract/difficult to understand & Concrete/understandable \\
\hline We have concerns about your parenting skills. & $\begin{array}{l}\text { - We want you to set up a daily schedule for your child that includes when he } \\
\text { eats, when he takes naps, and when he goes to bed. Let's write it down } \\
\text { together. } \\
\text { - What makes it hard for you to keep a schedule? Let's make a plan to fix that. } \\
\text { - Who can you call to ask for help? Let's write down their name and phone } \\
\text { number. }\end{array}$ \\
\hline $\begin{array}{l}\text { An ideal living situation for you would be a duplex or a } \\
\text { triplex. }\end{array}$ & $\begin{array}{l}\text { - A good place for your family to live is in a building that only has two or three } \\
\text { apartments. }\end{array}$ \\
\hline Are you watching what you eat? & $\begin{array}{l}\text { - What did you eat today, and how much? Let’s start with breakfast. } \\
\text { - Your doctor doesn't want you to drink any soda or juices. It's bad for your } \\
\text { blood sugar. } \\
\text { - Let's make a list of drinks that you like and are good for you. }\end{array}$ \\
\hline Are you clean and sober? & $\begin{array}{l}\text { - Here's a calendar. Can you show me the last time you drank any alcohol? } \\
\text { - Did you smoke weed yesterday? }\end{array}$ \\
\hline You need to check in regularly with your probation officer. & $\begin{array}{l}\text { - You need to call Diane's office every Tuesday by } 10 \text { a.m. Here's the phone } \\
\text { number. Let's program it into your phone to help you remember. } \\
\text { - Where else should we write this down, in case you lose your phone? } \\
\text { - I am going to call you the day before to remind you until you can remember } \\
\text { on your own. }\end{array}$ \\
\hline
\end{tabular}

The HVCM and service provider team continued to consult with each other on an ongoing basis, incorporating the neuropsychological assessment results and recommendations into their work with Nina in creative ways and adjusting their expectations accordingly. For example, in order to maintain her low-income housing voucher, Nina was required to keep her home clean and organized. She experienced difficulty doing this because she became easily overwhelmed by details. Knowing that it would not be helpful to simply tell Nina what to do and expect her to remember, the HVCM case manager and housing strategy used by most people to organize their households, and suggested that it might be helpful for her. The HVCM program then hired a one-time service to clean and organize Nina's apartment; the case manager took pictures of each room and helped Nina create checklists of the tasks required to clean each room. These materials were laminated and kept in places where Nina could refer to them as visual reminders of what needed to be checked off as she worked. For example, Nina's concept of a "clean kitchen" simply meant that the dishes were washed. Therefore, the kitchen checklist included tasks such as wiping countertops with a clean sponge, sweeping the floor, and emptying trash. After Nina began experiencing success with this system, she was motivated to create other checklists to help guide her through parts of the day that often became chaotic. For example, she laminated a list of detailed steps to help organize the morning routine with her sons before they left the house. As these steps started to become habits, Nina's household became more organized and peaceful. coordinator told Nina that keeping a "to do" list is a 
With ongoing support from the HVCM program, Nina experienced increasing stability in her life. She met with a mental health therapist on a regular basis, and was able to quickly regain her sobriety after a brief relapse. Nina applied for and was granted Social Security benefits, and was appointed a trusted payee who ensured that she was not taken advantage of financially. With assistance from the HVCM case manager, Nina enrolled her children in a therapeutic childcare facility that met their developmental and educational needs. Nina succeeded in demonstrating her competency as a parent, and her child welfare cases were closed.

This case study illustrates the ways in which clinicians responded to information about Nina's PAE and developmental history, the steps taken to accommodate her neuropsychological impairments, and the resulting impact on the quality of Nina's day-to-day life. The HVCM program has begun offering other clients with a history of $\mathrm{PAE} /$ suspected FASD an opportunity to participate in a comprehensive neuropsychological evaluation to assess cognitive functioning and learning styles, so as to individualize service planning. To date, 20 women have been evaluated, and eventually their outcome data will be compared with approximately $60 \mathrm{HVCM}$ clients with PAE who have not had neuropsychological testing but have had histories of social problems and adult behaviors consistent with FASD.

\section{Conclusion}

The value of a comprehensive neuropsychological evaluation for an adult who presents with a history like Nina's - especially when PAE is strongly suspected or confirmed-cannot be over-emphasized. Case conceptualization, diagnosis, and recommendations for treatment and intervention for adults with a suspected FASD should begin with a thorough clinical interview that includes specific questions about alcohol use by the client's mother during her pregnancy. This sensitive topic can be framed by first explaining to the client that while questions about her biological family may seem very personal, they are important because they can help the clinician understand challenges the client has encountered, in order to determine how to best help.

If PAE is suspected or confirmed, a neuropsychological assessment should be administered by a neuropsychologist with training and experience in working with adults with FASD. It is important that a timeline be established indicating the point at which the client's cognitive deficits presented, so that competing etiologies (e.g., history of abuse and neglect, drug use, head injury) may also be explored. In Nina's case, based on her report of early problems in school, it was determined that her intellectual and cognitive deficits predated problems that developed later as a result of a serious head injury she sustained while attempting to leave an abusive relationship.
It is essential to develop an interdisciplinary team approach in working with a person who has FASD (Kodituwakku, Kalberg, \& May, 2001). While the composition of the team depends on the client's situation, each professional involved should be encouraged to think creatively and incorporate knowledge unique to their discipline with what is known about the client's abilities, in order to develop strategies tailored to the individual. Ideally, a neuropsychologist should be included on the team, because of their knowledge of brain-behavior relationships.

Given the permanent nature of the disability, individuals with FASD will require, and should receive, some degree of coordinated care throughout their lifetimes. Quality of life for an adult with FASD may be substantially improved when assessment results and recommendations are shared with supportive family members and service providers, who can apply this information on a daily basis and build on the person's strengths while shoring up areas of weakness.

One of the most important lessons learned from this case study is that the results of a neuropsychological assessment can be used to empower adults with FASD to become their own advocates. A growing literature supports the importance of self-determination and self-advocacy among individuals with intellectual and developmental disabilities, and distinguishes the influences of personal characteristics (e.g., self-awareness, self-esteem, self-regulation) from environmental conditions (e.g., the physical setting, interpersonal dynamics) (Field, 1996; Nonnemacher \& Bambara, 2011; Test, Fowler, Wood, Brewer, \& Eddy, 2005; Wehmeyer \& Bolding, 2001; Wehmeyer \& Garner, 2003; Wehmeyer, Kelchner, \& Richards, 1996). Building on the work of Wehmeyer \& Bolding (2001), Nonnemacher and Bambara (2011) reported on the type and quality of interpersonal supports received from providers, and found that self-determination was supported and self-agency enhanced when clients with an intellectual disability were able to "speak out" and "be in charge." This occurred when professionals: (1) were approachable, accessible, and fostered trusting and secure relationships; (2) took the time to listen in supportive and nonjudgmental ways; (3) expanded options available, offering choices and encouraging decision-making; (4) provided support and encouragement for the clients to carry out their decisions; and (5) provided clients with access to the people in authority.

In Nina's case, the neuropsychologist was the first person to offer her the understanding of how prenatal alcohol exposure has impacted her cognitive, academic, social and adaptive functioning, and how this contributes to the dayto-day challenges she experiences. With the support of a knowledgeable and compassionate team, Nina now uses strategies and language more effectively to let others know how she learns best ("speak out") and what she needs from them in order to be more successful ("be in charge"). In doing so, Nina continues to experience a growing sense of self-confidence and autonomy. 


\section{References}

Aragon, A. S., Kalberg, W. O., Buckley, D., Barela-Scott, L. M., Tabachnick, B. G., \& May, P. A. (2008). Neuropsychological study of FASD in a sample of American Indian children: Processing simple versus complex information. Alcoholism: Clinical and Experimental Research, 32, 2136-2148. doi: 10.111/ j.1530-0277.2008.00802.x

Barr, H. M., Bookstein, F. L., O’Malley, K. D., Connor, P. D., Huggins, J. E., \& Streissguth, A. P. (2006). Binge drinking during pregnancy as a predictor of psychiatric disorders on the Structured Clinical Interview for DSM-IV in young adult offspring. American Journal of Psychiatry, 163, 1061-1065.

Brown, N. N., Connor, P. D., \& Adler, R. S. (2012). Conduct-disordered adolescents with fetal alcohol spectrum disorder: Intervention in secure treatment settings. Criminal Justice and Behavior, 39, 789-812.

Centers for Disease Control and Prevention (CDC) (2004a). Fetal alcohol syndrome: Guidelines for referral and diagnosis. Atlanta, GA, United States: Author

Centers for Disease Control and Prevention (CDC) (2004b). Alcohol consumption among women who are pregnant or who might become pregnant-United States 2002. Morbidity and Mortality Weekly Report, 53, 1178-1181.

Chudley, A. E., Conry, J., Cook, J., Loock, C., Rosales, T. \& LeBlanc, N. (2005). Fetal alcohol spectrum disorder: Canadian guidelines for diagnosis. Public Health Agency of Canada's National Advisory Committee on Fetal Alcohol Spectrum Disorder. Canadian Medical Association Journal, 172, S1-S21.

Clark, E., Lutke, J., Minnes, P., \& Ouellette-Kuntz, H. (2004). Secondary disabilities among adults with Fetal Alcohol Spectrum Disorder in British Columbia. Journal of FAS International, 2, 1-12.

Connor, P. D., Sampson, P. D., Bookstein, F. L., Barr, H. M., \& Streissguth, A. P. (2000). Direct and indirect effects of prenatal alcohol damage on executive function. Developmental Neuropsychology, 18, 331354.

Connor, P. D., Sampson, P. D., Streissguth, A. P., Bookstein, F. L., \& Barr, H. M. (2008). Effects of prenatal alcohol exposure on fine motor coordination and balance: A study of two adult samples. Neuropsychologia, 44, 744-751.

Conners, C. K., \& MHS Staff (2000). Conners' Continuous Performance Test II: Computer program for Windows technical guide and software manual. North Tonawanda, NY, United States: Multihealth Systems.

Delis, D. C., Kramer, J. H., Kaplan, E., \& Ober, B. A. (2000). California verbal learning test (2nd ed.). San Antonio, TX, United States: Pearson.

Derogatis, L. (1994). Symptom checklist-90-revised. San Antonio, TX, United States: Pearson.

Ernst, C. C., Grant, T. M., Streissguth, A. P., \& Sampson, P. D. (1999). Intervention with high-risk alcohol and drug-abusing mothers: II. Three-year findings from the Seattle model of paraprofessional advocacy. Journal of Community Psychology, 27, 19-38. doi:
10.1002/(SICI)1520-6629(199901)27:1<19::AIDJCOP2>3.0.CO;2-K

Fagerlund, A., Autti-Ramo, I., Kalland, M., Santtila, P., Hoyme, H. E., Mattson, S. N. \& Korkman, M. (2012). Adaptive behavior in children and adolescents with foetal alcohol spectrum disorders: A comparison with specific learning disability and typical development. European Child and Adolescent Psychiatry, 21, 221231. doi: 10.1007/s00787-012-0256-y

Famy, C., Streissguth, A. P., \& Unis, A. S. (1998). Mental illness in adults with fetal alcohol syndrome or fetal alcohol effects. American Journal of Psychiatry, 155, 552-554.

Field, S. (1996). Self-determination, instructional strategies for youth with learning disabilities. Journal of Learning Disabilities, 29, 40-52.

Floyd, R. L., O’Connor, M. J., Sokol, R. J., Bertrand, J., \& Codero, J. F. (2005). Recognition and prevention of fetal alcohol syndrome. Obstetrics and Gynecology, 106, 1058-1064.

Golden, C. (1978). Stroop Color Word Test. Lutz, FL, United States: PAR, Inc.

Grant, T. M., Ernst, C. C., \& Streissguth, A. P. (1999). Intervention with high-risk alcohol and drug-abusing mothers: I. Administrative strategies of the Seattle model of paraprofessional advocacy. Journal of Community Psychology, 27, 1-18. doi: 10.1002/(SICI) 1520-6629(199901)27:1<1::AID-JCOP1>3.0.CO;2-3

Grant, T. M., Youngblood Pedersen, J., Whitney, N., \& Ernst, C. C. (2007). The role of therapeutic intervention with substance abusing mothers: Preventing FASD in the next generation. In $\mathrm{K}$. O’Malley (Ed.), Attention deficit hyperactivity disorders and fetal alcohol spectrum disorders: The diagnostic, natural history and therapeutic issues through the lifespan (pp. 69-93). Hauppauge, NY, United States: Nova Science Publishers, Inc.

Heaton, R. K., Miller, S. W., Taylor, M. J., \& Grant, I. (2004). Revised comprehensive norms for an expanded Halstead-Reitan battery: Demographically adjusted neuropsychological norms for African Americans and Caucasian adults. Lutz, FL, United States: PAR, Inc.

Heaton, R. K., \& PAR Staff (2003). Wisconsin Card Soring Test Computer Version 4: Research Edition (WCST: CV4). Lutz, FL, United States: PAR, Inc.

Huggins, J. E., Grant, T., O’Malley, K., \& Streissguth, A. P. (2008). Suicide attempts among adults with fetal alcohol spectrum disorders: Clinical considerations. Mental Health Aspects of Developmental Disabilities, 11, 33-41.

Hutchinson, J., \& Marquardt, T. P. (1997). Functional treatment approaches to memory impairment following brain injury. Topics in Language Disorders, 18, 45-57.

Jirikowic, T., Gelo, J., \& Astley, S. (2010). Children and youth with fetal alcohol spectrum disorders: Summary of intervention recommendations after clinical diagnosis. Intellectual and Developmental Disabilities, 48, 330-344. doi: 10.1352/1934-9556-48.5.330 
Jones, K. L. \& Smith, D. W. (1973). Recognition of the fetal alcohol syndrome in early infancy. Lancet, 302, 999-101. doi: 10.1016/S0140-6736(73)91092-1

Jones, K. L., Smith, D. W., Ulleland, C. N., \& Streissguth, A. P. (1973). Pattern of malformation in offspring of chronic alcoholic mothers. Lancet, 1, 1267-1271.

Kodituwakku, P. W., Kalberg, W., \& May, P. A. (2001). The effects of prenatal alcohol exposure on executive functioning. Alcohol Research \& Health, 25, 192-198.

Malbin, D. (2002). Trying differently rather than harder: Fetal alcohol spectrum disorders ( $2^{\text {nd }}$ ed.). Portland, OR, United States: Author.

Mattson, S. N., Delis, D. C., \& Jones, K. L. (1998). Neuropsychological comparison of alcohol-exposed children with or without physical features of fetal alcohol syndrome. Neuropsychology, 12, 146-153.

Mattson, S. N., Goodman, A. M., Caine, C., Delis, D. C., \& Riley, E. P. (1999). Executive functioning in children with heavy prenatal alcohol exposure. Alcoholism: Clinical and Experimental Research, 23, 1808-1815.

May, P. A., Gossage, J. P., Kalberg, W. O., Robinson, L. K., Buckley, D., Manning, M., \& Hoyme, H. E. (2009). Prevalence and epidemiologic characteristics of FASD from various research methods with an emphasis on recent in-school studies. Developmental Disabilities Research Reviews, 15, 176-192. doi: 10.1002/ddrr.68

Meyers, J. E., \& Meyers, K. R. (1995). Rey Complex Figure Test and Recognition Trial. Lutz, FL, United States: PAR, Inc.

Nonnemacher, S. L., \& Bambara, L. M. (2011). "I'm supposed to be in charge": Self-advocates' perspectives on their self-determination support needs. Intellectual and Developmental Disabilities, 49, 327340. doi: 10.1352/1934-9556-49.5.327

O'Connor, M. J., \& Paley, B. (2009). Psychiatric conditions associated with prenatal alcohol exposure. Developmental Disabilities Research Reviews, 15, 225-234. doi: 10.1002/ddrr.74

O'Connor, M. J., Shah, B., Whaley, S., Cronin, P., Gunderson, B., \& Graham, J. (2002). Psychiatric illness in a clinical sample of children with prenatal alcohol exposure. The American Journal of Drug and Alcohol Abuse, 28, 743-754. doi: 10.1081/ADA120015880

Olson, H. C., Feldman, J. J., Streissguth, A. P., Sampson, P. D., \& Bookstein, F. L. (1998). Neuropsychological deficits in adolescents with fetal alcohol syndrome: Clinical findings. Alcoholism: Clinical and Experimental Research, 22, 1998-2012. doi: 10.1111/ j.1530-0277.1998.tb05909.x

Paley, B., \& O’Connor, M. J. (2011). Behavioral interventions for children and adolescents with fetal alcohol spectrum disorders. Alcohol Research and Health, 34, 64-75.

Pei, J., Job, J., Kully-Martens, K., \& Rasmussen, C. (2011). Executive function and memory in children with fetal alcohol spectrum disorder. Child Neuropsychology, 17, 290-309. doi: 10.1080/09297049.2010.544650

Rasmussen, C. (2005). Executive functioning and working memory in fetal alcohol spectrum disorder.
Alcoholism: Clinical and Experimental Research, 29, 1359-1367. doi: 10.1097/01.alc.0000175040.91007.d0

Rasmussen, C., \& Bisanz, J. (2010). The relation between mathematics and working memory in young children with fetal alcohol spectrum disorders. The Journal of Special Education, 45, 184-191. doi: 10.1177/ 0022466909356110

Reitan, R. (1979). Trail Making Test. Tucson, AZ, United States: Reitan Neuropsychology Laboratory.

Riley, E., Mattson, S., \& Thomas, J. (2009). Fetal alcohol syndrome. In L. Squire (Ed.), Encyclopedia of neuroscience (Vol. 4), (pp. 213-220). Oxford, United Kingdom: Academic Press.

Robinson, G. C., Conry, J. L., Conry, R. F. (1987). Clinical profile and prevalence of fetal alcohol syndrome in an isolated community in British Columbia. Canadian Medical Association Journal 137, 203-207.

Ruff, R. M. (1988). Ruff figural fluency test. Lutz, FL, United States: PAR, Inc.

Salmon, J. V., \& Buetow, S. A. (2012). An exploration of the experiences and perspectives of New Zealanders with fetal alcohol spectrum disorder. Journal of Population Therapeutics and Clinical Pharmacology, 19, e41-e50. Retrieved from: http://www.jptcp.com/ pubmed.php?articleId=356

Sampson, P. D., Streissguth, A. P., Bookstein, F. L., Little, R. E., Clarren, S. K., Dehaene, P., . . . Graham, J. M. Jr. (1997). Incidence of fetal alcohol syndrome and prevalence of alcohol-related neurodevelopmental disorder. Teratology, 56, 317-326.

Sparrow, S. S., Balla, D. A., \& Cicchetti, D. V. (1984). Vineland Adaptive Behavioral Scales, (Interview Edition). Circle Pines, MN, United States: American Guidance Services, Inc.

Spohr, H. L., Willms, J. \& Steinhausen, H. C. (2007). Fetal alcohol spectrum disorders in young adulthood. Journal of Pediatrics, 150, 175-179

Steinhausen, H. C. (1996). Psychopathology and cognitive functioning in children with fetal alcohol syndrome. In H. L. Spohr \& H. C. Steinhausen (Eds.), Alcohol, pregnancy and the developing child (pp. 227-246). Cambridge, Great Britian: University Press.

Steinhausen, H. C., \& Spohr, H. L. (1998). Long-term outcome of children with fetal alcohol syndrome: Psychopathology, behavior, and intelligence. Alcoholism: Clinical and Experimental Research, 22, 334-338. doi: 10.1111/j.1530-0277.1998.tb03657.x

Streissguth, A., Barr, H., Kogan, J., \& Bookstein, F. (1996). Understanding the occurrence of secondary disabilities in clients with fetal alcohol syndrome (FAS) and fetal alcohol effects (FAE). Final report to the Centers for Disease Control and Prevention. (CDC Rep. No. 96-06). Seattle, WA, United States: University of Washington, Fetal Alcohol and Drug Unit.

Streissguth, A. P., Bookstein, F. L., Barr, H. M., Sampson, P. D., O’Malley, K., \& Young, J. K. (2004). Risk factors for adverse life outcomes in fetal alcohol syndrome and fetal alcohol effects. Journal of Developmental and Behavioral Pediatrics, 25, 228238. doi: 10.1097/00004703-200408000-00002 
Stuss, D. T., Stethem, L. L., \& Poirier, C. A. (1987). Comparison of three tests of attention and rapid information processing across six age groups. The Clinical Neuropsychologist, 1, 139-152.

Test, D. W., Fowler, C. H., Wood, W. M., Brewer, D. M., \& Eddy, S. (2005). The conceptual framework of selfadvocacy for students with disabilities. Remedial and Special Education, 26, 43-54.

Watson, S. M. R., \& Westby, C. E. (2003). Strategies for addressing the executive function impairments of students prenatally exposed to alcohol and other drugs. Communication Disorders Quarterly, 24, 194-204. doi: 10.1177/15257401030240040501

Wechsler, D. (1997). Wechsler Adult Intelligence Scale ( ${ }^{\text {rd }}$ ed.). San Antonio, TX, United States: Pearson.

Wehmeyer, M. L., \& Bolding, N. (2001). Enhanced selfdetermination of adults with intellectual disability as an outcome of moving to community-based work or living environments. Journal of Intellectual Disability Research, 45, 371-383.

Wehmeyer, M. L., \& Garner, N. W. (2003). The impact of personal characteristics of people with intellectual and developmental disabilities on self-determination and autonomous functioning. Journal of Applied Research in Intellectual Disabilities, 16, 255-265.

Wehmeyer, M. L., Kelchner, K. K., Richards, S. (1996). Essential characteristics of self-determined behavior of individuals with mental retardation. American Journal of Mental Retardation, 100, 632-642.

Weinberger, J., Dolan, M., \& Dolan-Templeton, L. (2009). Returning to work after brain injury: A strategy guide for job coaches. North Brunswick, NJ, United States: Brain Injury Association of New Jersey.

West, D. D., \& Niemeier, J. (2005). Memory matters: Strategies for managing everyday memory problems. Richmond, VA, United States: Virginia Commonwealth University, National Resource Center for Traumatic Brain Injury.

Williams, R. J., Odaibo, F. S., \& McGee, J. M. (1999). Incidence of fetal alcohol syndrome in northeastern Manitoba. Canadian Journal of Public Health, 90, 192-194.

Woodcock, R. W., Mather, N., \& McGrew, K. S. (2001). Woodcock-Johnson Tests of Achievement ( ${ }^{\text {rd }}$ ed.). Itasca, IL. United States: Riverside Publishing. 